\title{
Editorial: Impacts of Tropical Landscape Change on Human Diet and Local Food Systems
}

\author{
Amy Ickowitz ${ }^{1 *}$, Bronwen Powell ${ }^{2}$, Laura Vang Rasmussen ${ }^{3,4}$ and Jeanine Rhemtulla ${ }^{3}$ \\ ${ }^{1}$ Center for International Forestry Research, Bogor, Indonesia, ${ }^{2}$ Department of Geography and African Studies, Pennsylvania \\ State University, University Park, PA, United States, ${ }^{3}$ Department of Forest and Conservation Sciences, University of British \\ Columbia, Vancouver, BC, Canada, ${ }^{4}$ Department of Geosciences and Natural Resource Management, University of \\ Copenhagen, Copenhagen, Denmark
}

Keywords: deforestation, forest conservation, land use change, diet, nutrition

\section{Editorial on the Research Topic}

\section{Impacts of Tropical Landscape Change on Human Diet and Local Food Systems}

\section{OPEN ACCESS}

Edited and reviewed by: Tapan Kumar Nath, University of Nottingham Malaysia Campus, Malaysia

*Correspondence: Amy lckowitz a.ickowitz@cgiar.org

Specialty section:

This article was submitted to Land, Livelihoods and Food Security,

a section of the journal

Frontiers in Sustainable Food Systems

Received: 22 December 2020 Accepted: 04 January 2021 Published: 28 January 2021

Citation:

Ickowitz A, Powell B, Rasmussen LV and Rhemtulla J (2021) Editorial: Impacts of Tropical Landscape Change on Human Diet and Local Food Systems.

Front. Sustain. Food Syst. 5:645241. doi: 10.3389/fsufs.2021.645241
The impacts of changing diets on land use and land cover has been an important area of research in recent years (Foley et al., 2011; Tilman and Clark, 2014; Fanzo and Davis, 2019; Willett et al., 2019). This special issue looks at the reverse side of this relationship - how land use change affects the diets of local communities living in landscapes where change is taking place. Clear links between forest cover and diet and nutritional outcomes have been shown (Johnson et al., 2013; Ickowitz et al., 2014; Rasolofoson et al., 2018; Fisher et al., 2019), while more recent work has started to disentangle the differential impacts of land use type, composition and configuration on diets and the consumption of specific food groups (Rasmussen et al., 2019; Gergel et al., 2020). This special issue brings together a collection of papers that examine the effects of land use and land use change on diet and nutritional outcomes in the tropics. It assembles papers from a wide range of disciplines, covering the links between forest conservation, deforestation, hydropower development, and changing patterns of agricultural production on diets and nutrition across a range of settings.

Rasolofoson et al. use data from the Demographic and Health Surveys (DHS) to examine the effects of forests on nutritional status, particularly stunting, across 25 low and middle-income countries. The authors compare the prevalence of stunting for children with and without access to forest, with access being defined as living in communities within $3 \mathrm{~km}$ of the nearest forest edge and with at least $30 \%$ forest within a $5 \mathrm{~km}$ radius around the community center. They find that the percentage of stunted children among those with access to forest is $30.25 \%$, while the stunting prevalence for children without access is $37.36 \%$. The authors argue that access to forest significantly reduces child stunting (at least $7.11 \%$ points average reduction) - and that forest conservation therefore is a potentially effective nutrition-sensitive intervention.

Like Rasolofson et al. and Borgerson et al. also argue that forest conservation can address malnutrition, but they reach this conclusion through concerns about the sustainability of bush-meat hunting. In their study of 13 communities in Masoala National Park in Madagascar, they find high rates of food insecurity and malnutrition as well as high reliance on forests for food, particularly wild meat. They also find that although forests make important contributions to 
nutrient consumption, the extraction rates for wild meat are unsustainable. They thus advocate for conservation to reduce unsustainable hunting by helping communities to gain access to domestic sources of nutrient-rich foods.

Using data from 1,783 households across seven sites (in Bangladesh, Burkina Faso, Cameroon, Ethiopia, Indonesia, Nicaragua, and Zambia), Baudron et al. examine the pathways through which forests contribute to household dietary diversity and consumption of fruits, vegetables, and meat. Using piecewise structural equation modeling, they compare the relative importance of a direct pathway (e.g., consumption of forest food), an income pathway (income from forest products used to purchase food from markets), and an agroecological pathway (forests and trees sustaining farm production). The results show major variation in the relationships between forest cover, pathways, and dietary outcomes across sites. Forest cover and dietary quality were positively related in some sites but negatively in others, and the importance of different pathways was also highly variable. The study highlights the significant variation in both the relationship between land use change and diets across settings, and the mechanisms that underly those relationships.

Rasmussen et al. examine how household wealth, on-farm production, and landscape context (forest cover and market access) are related to the dietary profiles of rural households in Ethiopia. Through cluster analysis of data from the World Bank's Living Standard Measurement Survey (LSMS), they identify three main household diet types: low diversity; high diversity rich in fruits and vegetables; and high diversity with increased consumption levels of oils, fats and sugars. The low diversity diet was mostly found among low- to middle-wealth households who farmed cereal grains. Households with diverse fruit-vegetable diets were most often engaged in coffee-agroforestry farming and tended to live in landscapes with higher forest cover. Finally, households with highly diverse oil-sugar diets tended to be wealthier and situated closer to roads. The study highlights the complex interactions among factors correlated with diverse diets and shows how even small increases in forest cover can increase dietary diversity and consumption of healthy foods.

While the previous papers look at how and under what conditions forests contribute to diets, Friant et al. and Acharya et al. investigate what happens to diets and nutrition when these forests are lost.

Friant et al. bring to light the ways in which dietary patterns differ across intermediate stages of deforestation and market integration in Cross River State in Nigeria. Using data on dietary diversity and food access collected from 528 households across six communities, they find that although forest-edge communities consumed less green leafy vegetables and less bushmeat than forest-interior communities, they consumed more dairy, eggs, beans, and other fruits and vegetables. Also, households from forest-edge communities exhibited significantly lower household food insecurity access scores. They conclude that in the intermediate stages of deforestation, communities may be able to get the "best of two worlds" with increased access to markets and continued access to forests.
Acharya et al. use Demographic and Health Survey data from 15 countries in Sub-Saharan Africa to explore the relationships between deforestation and the double burden of malnutrition. They find that forest cover loss is marginally associated with a higher probability of having an overweight woman and a stunted pre-school child in the same household, but not with having an overweight and anemic woman or an overweight and stunted child in the same household.

Golden et al. expands the focus of this collection of papers by examining dams as a unique form of land use change with the potential to have major impacts on human diets. Their paper examines the impact of dams on aquatic food resources in the Lower Mekong Basin (LMB), where over 100 dams are planned or in construction. Expanding on past modelling, they estimate that the loss of subsistence fish resources associated with dam building could greatly increase the number of people in the LMB who are at risk of protein, zinc, thiamine, niacin, calcium and iron deficiency.

Like Friant et al. and Sibhatu also finds some positive effects of land use change on diets. Sibhatu analyzes the impacts of oil palm adoption on about 700 households in Jambi, Indonesia over a 2-year period. He finds that oil palm adopters consumed more diverse foods at a household level than non-adopters and that they were less likely to be undernourished or to be micronutrient inadequate. This shows the potential positive effects of some land use changes; however, as Sibhatu himself (Sibhatu, 2020) and others have noted (Nurhasan et al., 2020), these findings may be very specific to the sample here in which both adopters and non-adopters of oil palm primarily cultivated plantation cash crops as opposed to food crops (Purwestri et al., 2019).

Finally, Sunderland and Vasquez address conservation of forests, warning against an overly protectionist stance that may have negative impacts on the food and nutrition security of local communities in forest-protected adjacent areas. After reviewing the many ways that forests contribute to the food and nutrition security of forest adjacent communities, they lay out some of the tensions between the conservation community and local people when protection of forests reduces access to forests for local communities that rely on them for their food and nutrition security. They call for greater integration and respect for the rights of local communities to access forests for food and a rightsbased and participatory approach to conservation that emphasizes synergies between biodiversity conservation and food security.

As a collection, these papers have several implications for research and policy. Although previous papers examining large secondary data sets have shown fairly consistent relationships between forest cover, land use, and diet quality (Johnson et al., 2013; Ickowitz et al., 2014; Galway et al., 2018; Rasolofoson et al., 2018), this collection of new papers suggests that the impact of land use change on diet quality and food systems is heterogenous. The context-specific trajectories that explain these different results across sites remain very poorly 
understood and are fueling a dynamic area of research as several of these studies show. Understanding these complex relationships is imperative for designing policies that ensure peoples' access to sustainable sources of sufficient quantities of nutritious foods.

\section{AUTHOR CONTRIBUTIONS}

All authors contributed equally to this editorial and to editing the special issue.

\section{REFERENCES}

Fanzo, J., Davis, C. (2019). Can diets be healthy, sustainable, and equitable? Curr. Obes. Rep. 8, 495-503. doi: 10.1007/s13679-019-00362-0

Fisher, B., Herrera, D., Adams, D., Fox, H. E., Gallagher, L., Gerkey, D., et al. (2019). Can nature deliver on the sustainable development goals? Lancet Planetary Health 3, e112-e113. doi: 10.1016/S2542-5196(18)30281-X

Foley, J. A., Ramankutty, N., Brauman, K. A., Cassidy, E. S., Gerber, J. S., Johnston, M., et al. (2011). Solutions for a cultivated planet. Nature 478, 337-342. doi: 10.1038/nature10452

Galway, L. P., Acharya, Y., Jones, A. D. (2018). Deforestation and child diet diversity: a geospatial analysis of 15 Sub-Saharan African countries. Health Place 51, 78-88. doi: 10.1016/j.healthplace.2018.03.002

Gergel, S. E., Powell, B., Baudron, F., Wood, S. L., Rhemtulla, J. M., Kennedy, G., et al. (2020). Conceptual links between landscape diversity and diet diversity: A roadmap for transdisciplinary research. Bioscience 70, 563-575. doi: 10.1093/biosci/biaa048

Ickowitz, A., Powell, B., Salim, M. A., and Sunderland, T. (2014). Dietary quality and tree cover in Africa. Global Environ. Change 24, 287-294.

Johnson, K. B., Jacob, A., and Brown, M. E. (2013). Forest cover associated with improved child health and nutrition: evidence from the Malawi Demographic and Health Survey and satellite data. Global Health Sci. Pract. 1, 237-248. doi: 10.9745/GHSP-D-13-00055

Nurhasan, M., Pawera, L., Lo, M., Pratama, M. F., Rahmah, M., Utami, M. M. H., et al. (2020). Commentary: oil palm boom and farm household diets in the tropics. Front. Sustain. Food Syst. 4:39. doi: 10.3389/fsufs.2020.00039

Purwestri, R. C., Powell, B., Rowland, D., Wirawan, N. N., Waliyo, E., Lamanepa, M., et al. (2019). From growing food to growing cash: understanding the drivers of food choice in the context of rapid agrarian change in Indonesia. CIFOR Infobriefs 263, 1-3. doi: 10.17528/cifor/007360

\section{FUNDING}

This was funded by USAID grant number: AID-BFS-IO-1700005 .

\section{ACKNOWLEDGMENTS}

This work was part of the CGIAR research program on Forests, Trees and Agroforestry. AI gratefully acknowledges support from the United States Agency for International Development's Forest and Biodiversity Office.

Rasmussen, L. V., Fagan, M. E., Ickowitz A., LR Wood, S. L. R., Kennedy, G., Powell, B., Baudron, F. et al. (2019). Forest pattern, not just amount, influences dietary quality in five African countries. Glob. Food Sec. 2019:100331. doi: 10.1016/j.gfs.2019.100331

Rasolofoson, R. A., Hanauer, M. M., Pappinen, A., Fisher, B., and Ricketts, T. H. (2018). Impacts of forests on children's diet in rural areas across 27 developing countries. Sci. Adv. 4:eaat2853. doi: 10.1126/sciadv. aat 2853

Sibhatu, J.T. (2020). Commentary: oil palm boom and farm household diets in the tropics. Front. Sustain. Food Syst. 3:75. doi: 10.3389/fsufs.2020. 00107

Tilman, D., and Clark, M. (2014). Global diets link environmental sustainability and human health. Nature 515, 518-522.

Willett, W., Rockström, J., Loken, B., Springmann, M., Lang, T., Vermeulen, S., et al. (2019). Food in the anthropocene: the EAT-lancet commission on healthy diets from sustainable food systems. Lancet 393, 447-492. doi: 10.1016/S0140-6736(18)31788-4

Conflict of Interest: The authors declare that the research was conducted in the absence of any commercial or financial relationships that could be construed as a potential conflict of interest.

Copyright (C) 2021 Ickowitz, Powell, Rasmussen and Rhemtulla. This is an open-access article distributed under the terms of the Creative Commons Attribution License (CC BY). The use, distribution or reproduction in other forums is permitted, provided the original author(s) and the copyright owner(s) are credited and that the original publication in this journal is cited, in accordance with accepted academic practice. No use, distribution or reproduction is permitted which does not comply with these terms. 